DOI: $10.20472 / I A C .2020 .054 .013$

\author{
NEBOJŠA JANIĆIJEVIĆ \\ Faculty of Economics, University of Belgrade, Serbia
}

\title{
THE IMPACT OF ORGANIZATIONAL CULTURE ON FIRM PERFORMANCE: ORGANIZATIONAL CULTURE AS A MAGIC WAND OR SILENT KILLER?
}

\begin{abstract}
:
The paper analyses the impact of organizational culture on company performances. The theoretical basis that organizational culture impacts company performance has been found in the fact that company's organizational culture as part of its intellectual capital determines its ability to build core competence and thereby gain competitive advantage on the market. The review of research made in the field so far shows that this impact exists, but it is lower in intensity than it has intuitively been presumed. Also, since organizational culture and performance are in themselves highly complex, multidimensional variables, hence their relation is also multilayered, multidimensional, and complex. Numerous methodological shortcomings in the research of organizational culture, performance and their relationship, however, put doubt on some of the research results.
\end{abstract}

\section{Keywords:}

Organizational culture, Performance, Company, Intellectual capital, Resource theory, Research methodology

JEL Classification: M14, M10 


\section{Introduction}

Organizational culture as a management concept was for the first time systematically researched and defined in the works of the late 1970s and early 1980s (Pettigrew, 1979). From then on, an enormous number of research as well as papers on the nature, content, dynamics, and impact of organizational culture have been published. Since organizational culture is a very complex and multidimensional phenomenon, it is no surprise that different perspectives, approaches, and even paradigms of organizational culture appear in the literature (Martin 2002; Alvesson 2002). However, mainstream thinking concerning organizational culture has adopted certain views regarding its nature, content, and effects. First, organizational culture is thought to involve a set of values and norms that are expressed through symbols shared by the organization members (Hofstede et al. 1990). Second, because organizational culture is a collective rather than an individual construct, its content is created through social interactions among members of particular groups (Schein 2004). Third, the values and norms shared by organization members significantly shape their thoughts and behavior (Schein 2004). Cultural values as inspirational ideals (Rokeach 1973) and cultural norms as specific social expectations governing behavior (Balthazard, Cooke, \& Potter 2006; Hofstede et al. 1990) guide organization members in understanding and interacting with people, phenomena, and events. The everyday decisions managers and employees make, the actions they take, and the interactions they engage in are in large part determined by the values and norms of the organizational culture. Even if they themselves do not share the predominant values and norms, the organization members cannot ignore them because the organization sanctions behavior that deviates from its values and norms.

In order to understand the impact of organizational culture on organization's functioning as well as on organizational performance, it is necessary to explore the relations between culture and meanings as one of the determinants of thinking and behavior of organization members. Organizational culture is, in fact, a kind of reservoir for collective meanings in an organization, which determine every collective and individual action and decision (Peterson \& Smith, 2000; Louis, 1985; Smircich, 1983). Organizational culture emerges in the process of social interactions of the organization members in which they construct the reality together (Geertz, 1973). According to Schein (2004), this process occurs during solving the key issues of external adaptation and internal integration which members of every organization face. In the process of social construction of reality, the organization members together ascribe meanings to occurrences, people, and events within and outside of the organization in order to interpret and understand them. Depending on the meanings that the organization members collectively ascribe to the realities they face, they will also act in a certain way in that reality. (Louis, 1985; Smirchich, 1983). The comprehensiveness of organizational culture's impact on people's behavior in organizations emerges from every single action, reaction, or decision of each member of organization being, to some extent, conditioned by the meanings imposed on people in the organization by the organizational culture (Alvesson, 2002). Due to all of this, organizational culture is a very powerful means for shaping of organization members' behavior, and thereby also for all the processes within the organization that generate its performance.

Through its influence on the decisions, actions, and interactions of managers and employees, organizational culture also impacts different aspects of management and organization. Extensive empirical research has documented that organizational culture affects strategy (Klein 2011; Yarbrough, Morgan, Vorhies 2011; Baird, Harrison, Reeve 2007), performance control (Deem et al. 2010), organizational structure (Ranson, Hinings, 
Greenwood 1980), compensation systems (Wright A. (2010), performance appraisal (Henri 2006), organizational learning (Alavi, Kayworth, Leidner, 2006); leadership (Giberson et al. 2009; Berson, Oreg, Dvir 2008), and job satisfaction (Lund, 2003).

Since it impacts the above stated as well as some other aspects of management, it is highly likely that culture also impacts organizational performance (Wilderom, Glunk, Maslowski 2000). Since the very beginnings of research into this concept, researchers were aware that culture can be a management's tool for achieving high performance. This awareness is based on three implicit assumptions that stand as foundation to most research dealing with the problem of relations between organizational culture and performance (Wilderom, Glunk, Maslowski 2000). First, there is the assumption that some organizational cultures imply better performance than other organizational cultures. This means that culture is the factor that could explain, at least in some part, the differences in performance of different companies and that, hence, there is indeed a causal relationship between these two concepts. Second, it is possible to identify a particular attribute of organizational culture that leads to better performance. Therefore, through either experience or research, we may come to know what kind of culture leads to better performance. The third assumption is that organizational culture is prone to changes and management, that is, it can be changed and shaped in the direction that leads to better performance. The literature overview shows, however, that despite the "obviousness" of the impact of culture on organizational performance, the results of research into this impact are not so clear and unambiguous. Also, despite an obvious progress in the research of the culture's impact on company performance, the said impact remains somewhat unrevealed and problematic.

The aim of this paper is to explain the way in which organizational culture impacts company performance and to present the results of the existing research into this topic. Therefore, the theoretical framework of the organizational culture's impact on performance will be presented first; it will be followed by a presentation of the basic knowledge on the relations between culture and organizational performance reached by researchers thus far. Finally, numerous methodological issues in the research into organizational culture's impact on performance will be presented.

\section{Theoretical Framework of Organizational Culture's Impact on Performance}

The theoretical framework of the organizational culture's impact on company performance can be found in the frameworks of the firm's resource perspective. In the firm's resource perspective, company resources are the key for its success and survival. A company can achieve high performances only if it has competitive advantage, while the source of its competitive advantage is tangible and intangible resources at its disposal, which are scarce, valuable, sustainable, and difficult to imitate (Zheng, Yang, McLean, 2010). Organizational culture is a part of intangible resources, that is, intellectual capital that can be defined as "... sum of everything that everyone within the organization knows and that enables the organization to create competitive advantage on the market" (Sundac, Fatur Krmpotic, 2009, pp 280). Although intellectual capital has been defined and studied in the literature from various perspectives, there is a certain consensus concerning its following characteristics: 1 ) intellectual capital is intangible, invisible, and has no physical form; 2) intellectual capital is not necessarily owned by the organization, but it may be informally engaged; 3 ) it is the sum of intangible resources and their flows that are not calculated in financial reports; 4) 
intellectual capital is a strategic source of sustainable competitive business performances because it is idiosyncratic, nontransferable, cannot be copied or imitated, and cannot be substituted; 5) it consists of a wide range of characteristics and dimensions that can be grouped by particular categories of intangible resources (Bontis, 1999; Sonnier, 2008; Martín de Castro, et al, 2011). Bontis $(1998,1999)$ views intellectual capital as a construct composed of three dimensions: human, structural, and relational capital. While human capital may be defined as the quality of employees' knowledge, skills, and abilities (Brooking, 1997), and relational capital as company's ability to create and maintain stable relationships with the buyers and other stakeholders in the environment (Marr, 2006), structural capital concerns the knowledge that stays within the organization even after the employees go home at the end of the day, and even when they permanently leave the organization. When applied within the organization, the employees' knowledge, or human capital, creates structural capital which, in turn, can be used to increase organization's competitive advantage and create value for the organization. Structural capital (Bontis, 1998, 1999) allows for individual human capital, individual knowledge, to be used over and over again in order to create value. Strategy, organizational structure, organizational systems, organizational routines, standardized practices and procedures, as well as organizational culture can be categorized as elements of structural capital (Stewart, 1997). Organizational culture is, therefore, unavoidable element of structural capital because it functions as a "glue which keeps the entire organization together" (Cabrita, Bontis 2008, p. 219). As part of structural capital, organizational culture has the critical role in creating competitive advantage and, based on that, achieving high company performance. It plays this role through building key competencies through which the company manages to perform business processes in a superior way comparing to that of its competitors.

In contemporary market conditions, the only permanent source of competitive advantage for a company in the market is its ability to conduct the business processes from the value chain in a way which is superior comparing to its competitors (Porter, 1985). Superiority in conducting business processes leads to creating added value for the consumer, which is difficult or impossible to imitate, and thus the company gains competitive advantage in the market (Hamel, Prahald, 1994). In turbulent conditions of rapid changes, the company gains competitive advantage in the market not because it has something that other companies do not have, but because it can and knows how to do something better than others. The thing that the company can and knows how to do better than its competitors is its core competence, which represents the source of its competitive advantage in the market (Freiling, Fichtner, 2010). How will the company perform business processes, such as purchase, production, sales, but also logistics, information processing, organizational learning, organizational changes, etc., it largely depends on organizational culture. Since organizational culture determines the meanings that the members of organization ascribe to the reality within and outside of the organization, and since they make their decisions, take action, and enter mutual interactions based on these meanings, this means that organizational culture shapes all the processes within the organization. Through its assumptions, values, norms, and attitudes shared by the employees and managers, the culture shapes their everyday behavior, practices, and routines in performing work tasks, and it thus also shapes business processes. Thereby, the culture determines if the business processes in the company would be performed in a way that leads to competitive advantage. We may, therefore, say that organizational culture is one of the key factors in company's core competence. What is especially important is that organizational culture of every 
company is idiosyncratic because it originated from its own unique experience. From the very beginnings of research, culture has been defined as "the way we do it here", suggesting that the culture implies a unique way of working and living within the organization. This, in turn, makes culture the source of core competence which is very difficult to imitate by the competition. Thereby, organizational culture becomes "that one thing", that is, "the secret ingredient" in the formula of company's success. This was, indeed, clear from the very beginning of the researching into organizational culture, so many authors have emphasized organizational culture as the "magic wand" of company's success, and it was regularly classified among the sources of business success (Peters, Waterman, 1982).

Besides direct impact on performance through shaping of business processes, organizational culture also indirectly impacts successfulness of the company. Namely, by determining decisions, actions, and interactions between management and employees, organizational culture not only directly shapes business processes, but it also influences many aspects of organization and management that are also determinants of business processes. As previously noted, organizational culture determines company strategy, the way in which its organizational structure is shaped, system of control and coordination, leadership style, motivation profile, job satisfaction, reward system, employees' performance appraisal, organizational learning and knowledge management model, power distribution in the organization, and organizational change management. By impacting all of these hard and soft organizational elements of a company, organizational culture also impacts the business processes, and thereby company performance as well. The elements of management and organization, such as strategy, structure, leadership, and human resources management (HRM) systems, are the framework in which business processes that should lead to competitive advantage and company performance unfold. As a framework, they certainly to some extent determine the way in which business processes will take place, as well as their performance. Since organizational culture determines the stated elements of company organization and management, it thereby also indirectly impacts business processes, and thus also the company performance as well. 


\section{Figure 1. Theoretical framework of organizational culture's impact on company's performances}

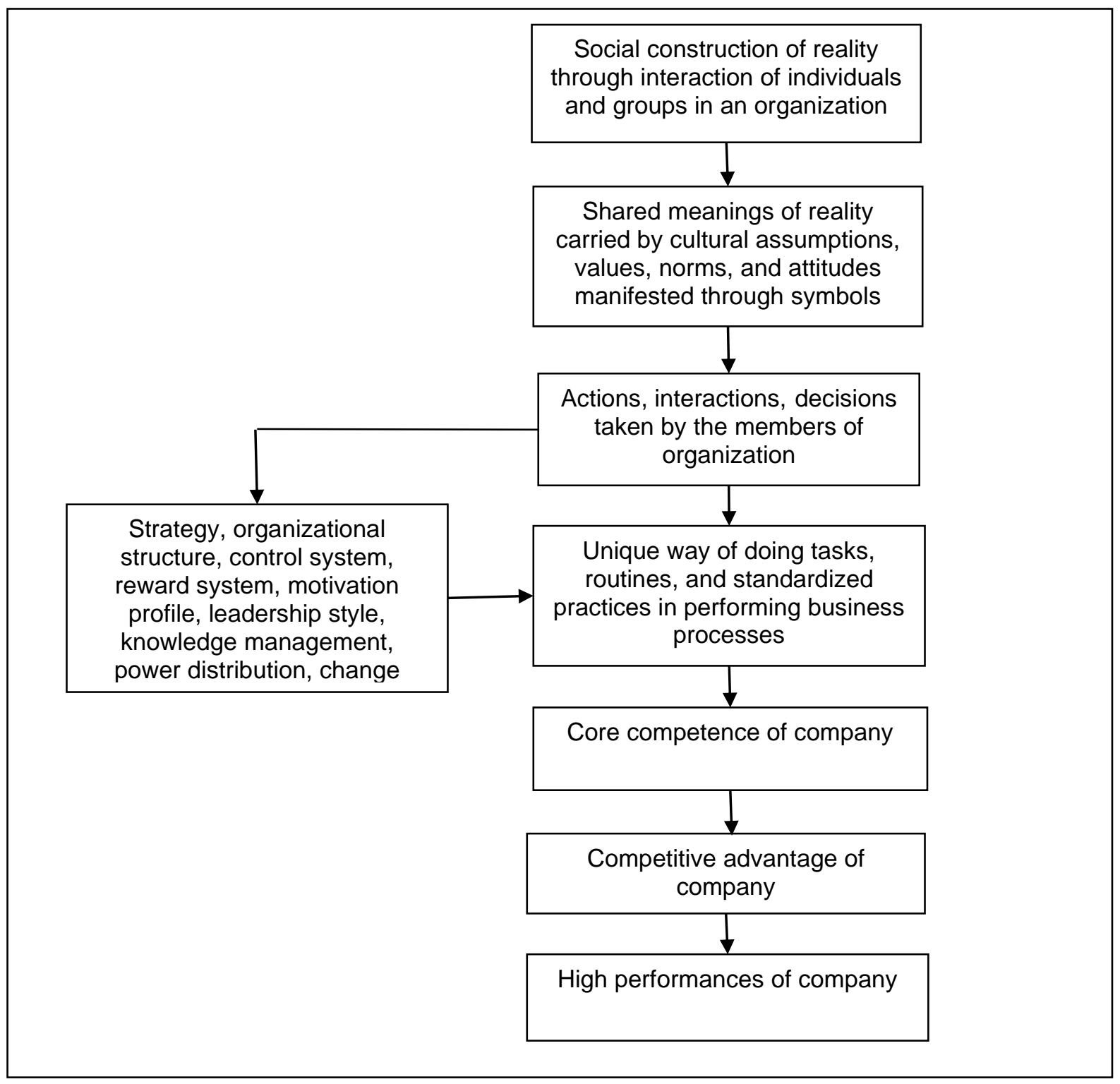

\section{Results of the research into organizational culture's impact on performance}

Research into the impact of organizational culture on organizational performance has thus far undergone three phases (Sackmann, 2011). In the first phase, there were many uncritical and intuitive writings about the relationship between culture and performance of an organization. This phase lasted from the very beginning of writings about organizational culture until 1982. Back then, the impact of organizational culture on company performance was taken for granted and it was not empirically examined. Japanese economic boom and success of its companies at that time significantly contributed to the acceptance of the assumption about the impact of culture on performance. Ouchi (1981) pointed out the importance of some elements of organizational culture of Japanese companies for their success (lifelong employment, loyalty to the company, strong vision). In this phase, the culture's strength, rather than its content, was considered the key factor of the culture's impact on performance. The last in the series and the most well-known work that assumed 
the importance of culture's strength for organization's success was the famous book "In Search of Excellence" by Perets and Waterman, published in 1982. After 1982, however, began the phase of questioning and refuting in the explorations of culture's impact on organizational performance. In the period from 1982 to 1990, there were many works with highly critical analyses of the impact of culture on performance in which this impact was questioned and, more or less, refuted. What is interesting is that these refutations were more theoretical and intuitive than empirical. The very authors who propagated causal relations between culture and performance significantly contributed to these refutations because they did not have a valid methodological ground for their findings, so they were relatively easy to criticize. Finally, the phase of empirical research of organizational culture's impact on performance begins from 1990. From the early 1990s, more and more empirical researches were appearing in which a true measure of the culture's impact on performance was found without exaggeration, and also without unnecessary refutations.

The research into organizational culture's impact on performance in contemporary period are characterized by the following trends (Sackmann, 2011):

- Research is becoming more and more globalized. The culture's impact on performance of companies and other organizations is being researched not only in the United States, but in other countries too. This is especially important because one of the moderating factors of the culture's impact on performance is, by all means, national culture.

- Research is becoming more and more specialized. More and more studies investigate the impact of individual components, rather than the impact of the entire culture, on individual aspects of performance. In addition, research is being conducted in individual sectors of economy, in individual national cultures, and in specific contexts, such as joint ventures and the like.

- Research methodology is becoming more and more sophisticated. While researchers in early empirical research mainly relied on simple statistical analyses, they now increasingly use structural equations as their research method. Research now has clearer and more soundly founded theoretical background, and the number of longitudinal research is also increasing.

- Research programs of exploring culture's impact on performance are also emerging. These programs generate several research streams that start from the same theoretical bases and use the same methodology, so their results can, therefore, be compared and accumulated. One example of this is the Denison model of culture's impact on performance based on Denison Organizational Culture Survey (Denison, Mishra, 1995).

The research conducted thus far on the impact of organizational culture on performance has shown that the impact is multidimensional, complex, and multiform. Above all, organizational culture influences performance directly. Culture achieves this impact through its particular content (assumptions, values, and norms), culture type (configuration), culture strength, and cultural gap. However, the impact of organizational culture on performance may also be indirect, through some other management components. The relationship between organizational culture and performance can also be reciprocal, because it is not only that culture influences performance, but also performance influences the culture. Finally, the 
impact of organizational culture on performance may be altered due to influences of many moderating or mediatory variables.

The main question concerning direct impact of organizational culture on performance is the following: What is the thing through which organizational culture impacts performance level? The existing research has given four possible answers (Wilderom et al., 2000). First, culture impacts performance through its content: individual assumptions, values, or norms. Second, culture impacts performance through its configuration, and not through individual elements of content, which means that a certain type of organizational culture - and not its individual assumptions, values, or norms within its content - represents the factor which directs performance. Third, culture strength - and not culture type - is the factor which directs performance of organization. Finally, some researchers have focused their attention on cultural gap, that is, the difference between the existing and the ideal culture, as the factor of organizational performance. The results of all four (4) directions of research will be shortly presented.

If we start from the assumption that different cultures imply different performance, the first thought that comes to our minds is to identify what assumptions, values, or norms lead to better performance. Then the managers would only have the task to incorporate these assumptions, values, and norms into the cultures of their organizations, and thereby improve the organization's performance. Research has identified a wide spectrum of assumptions, values, and norms that bear proven positive implications on organizational performance. All elements of cultural content that influence performance may be divided into external and internal. Among external assumptions, values, and norms regulating the relations between the company and its environment are adaptability, openness, change acceptance, market orientation, consumer care, innovativeness, and quality orientation. One research has shown, for example, that the focus on consumers and their needs explains as much as $45 \%$ of EBITA variations between different companies (Flamholtz, Kannan-Narasimhan, 2005). On the other hand, internal assumptions, values, and norms regulating the internal relations within an organization and behavior of its members also impact organizational performance. Among internal elements of organizational culture, the following have the strongest impact on performance: involvement, mission, identifying with the organization, innovativeness, employees' learning and development, humanistic orientation, achievement orientation, employees' cooperation, and team spirit (Ginevičius, Vaitkūnaitè, 2008). In the abovementioned research, for example, it was proven that $22 \%$ of EBITA variations was due to the employees' identifying with the company (Flamholtz, Kannan-Narasimhan, 2005). Certainly, external and internal assumptions, values and norms should not be treated separately. Culture achieves the greatest impact on organizational performance when it has a certain combination of external and internal values. Thus, one research has shown that a combination of adaptability, market orientation, and orientation to consumers, on the one hand, and innovativeness and identifying with the company, on the other, is the best guide to better performance.

A number of researchers show that individual values and norms cannot separately lead to better performance, but only their configuration can (Tsui, Wang, Yin, 2006). The reason for this is, certainly, internal consistency of cultural content, that is, the fact that assumptions, values, and norms within the organizational culture's content must be mutually harmonized. Configurations of mutually consistent assumptions, values, and norms are nothing other than organizational culture types. A number of researchers have focused on identifying culture 
types that lead to better performance. These researchers always start with certain classification of cultural models and identify which one implies better performance. In addition, most of such research imply contingency of the relations between culture and performance (Sackmann, 2011). In other words, the impact of culture on performance depends on the context; hence, different types of culture will lead to better performance in different situations. The lesson for management is that there is no single ideal culture type that always leads to better performance, but that they should strive to the type which is adapted to the given situation and, therefore, leads to better performance. As contextual variables, that is, situational characteristics that determine the impact of culture on performance, the following has mostly been explored: sector in which company operates, national culture, and company size. Thus, for example, one group of authors has determined that organizational culture type impacts individual performance (job satisfaction, communication, clear roles) and organizational performance (product quality) (Balthazard, Cooke, Porter, 2006). As the basis for research, the classification of organizational cultures that recognizes three (3) main models was used: 1. Constructive type of culture characterized by people entering interactions with each other in the way which will enable them to satisfy higher needs, such as achievement; 2. Passive-defensive type of culture characterized by people entering interactions with each other in the way which will help them protect their safety; 3. Aggressive-defensive type of culture characterized by people being aggressive in their striving to defend their status and safety. The research unambiguously confirmed that constructive type of organizational culture positively impacts both individual and organizational performance, while both defensive models of culture negatively impact performance at both levels. Numerous researchers have, as their basis, used the types of culture identified within the competing values framework: clan, market, adhocracy, and hierarchy cultures (Gregory et al., 2009). In addition, a systematic impact that different types of culture have on performance has been discovered. Generally speaking, competitive culture types, such as market culture, have a positive impact, while bureaucratic culture types (hierarchy culture) have a negative impact on organizational performance.

From the earliest research into organizational cultures, it was believed that culture impacts performance not so much through its content as much as through its strength (Denison, Mishra, 1995; Kotter, Heskett, 1992). Namely, the first assumption on culture's impact on performance was that strong culture produces better performance and that more successful companies differ from the unsuccessful ones precisely because they have strong cultures. The influential research by Peters and Waterman, published in the bestseller "In Search of Excellence", significantly contributed to this assumption. By exploring what do all successful companies from the Fortune 500 List of the most successful companies have in common, they determined that, among ten (10) selected factors, strong organizational culture holds a very important position. Theoretical justification for this hypothesis was mainly based on the belief that strong culture creates consistency in actions, clarifies the direction of company's operations and mission, as well as that it creates the feeling of belongingness to the company, improves motivation, acts like an extremely powerful coordination mechanism, decreases conflicts, and improves work moral. However, there have been neither many nor persuasive research that has proven these assumptions. It was as if somehow the assumption on the impact of culture's strength on performance was believed in even without proving it, so there were not many researchers that actually explored this relation. Only three (3) out of 55 studies presented in a relevant review contained the relation between culture strength and performance (Sackmann, 2011). However, even these scarce studies have 
given mixed, and not very convincing results. In addition, different researches provided different answers to the crucial research question: What is culture strength and how is it measured? Thus, in one research, culture strength is measured through the extent to which the organization members share the same perceptions; in another research, culture strength is measured through the degree in which the organization members are getting along well; in yet another research, culture strength is measured through the degree of homogeneity in behavioral practices. Different definitions of the main variable being explored have disabled accumulation of the results of these researches and their mutual expansion based on one another. In addition, some authors gave a perfectly reasonable warning that strong culture does not have to be only a "magic wand of success", but that it can also be a "silent killer", that is, the culture's strength could also lead to company's failure, and not just to its success. The reason for this lies in the fact that a strong culture may block changes and prevent adaptation of the company to the changed conditions in the environment (Schein, 2004).

Cultural gap was the solution for unconvincing results of the research into the impact of organizational culture strength on performance (Kwantes, 2007). Namely, if culture strength is not in itself such a significant factor in performance, the following question arises: Could it, perhaps, be the gap between the existing and ideal or desired culture? Such research consisted of measuring the differences between the perceived and the targeted, desired, or ideal cultural values or norms, and then testing the impact of these differences on performance. Certainly, the starting hypothesis is always the following: The greater the cultural gap, the poorer the performance. However, just as in the case of exploration of culture strength, a relatively small number of research into this topic has produced mixed results.

Research into organizational culture impact on performance has shown that this impact is not only direct, but that it can also be indirect. Namely, organizational culture does not have to influence performance only directly, through its content, type, strength, or gap, but also indirectly through some other variables of organizational behavior and management, such as leadership (Berson, Oreg, Dvir, 2008). Research has shown that organizational culture impacts performance through creating the conditions for emergence of transformational leadership in organization. Unlike transactional leadership, transformational leadership is characterized by a clear and strong vision, inspiring of the followers, and changes. Research shows that a certain type of culture implies better performance in dynamic and turbulent conditions not only directly, but also indirectly by creating the environment for emergence of transformational leadership. Also, culture impacts better performance through innovations and market effectiveness (Sorensen, 2002). A certain type of culture is, indeed, better suited for company's innovativeness and market orientation, whereby it indirectly contributes to better performance. For example, one research has shown that adhocracy and entrepreneurial cultures imply higher new products' profitability, while bureaucracy and hierarchy cultures have a negative impact on this indicator.

Research shows that organizational culture also has an interactive impact on performance, together with other components of organization and management (Sackmann, 2011). Namely, when organizational culture works in the same directions with some other management systems or practices, their common impact is stronger than their separate individual impact would be. Therefore, here, we are talking about synergic effect of the impact of organizational culture and other components of management that have a high correlation between them. These are usually the components through which culture also 
indirectly impacts organizational performance. Research has identified several such components: leadership, organizational structure, human resource management practices and policies. For example, research has shown that flexibility of human resource management practices and policies is suitable for development of adaptive organizational culture, and vice versa. Also, both culture and human resource management jointly impact performance improvement.

Finally, organizational culture also has a reciprocal relationship with company performance (Sackmann, 2011). Besides the fact that organizational culture impacts performance, performance also impacts organizational culture. The literature in the field of organizational culture has long ago determined that good organizational performance leads to strengthening of the existing culture. Schein (2004) even claims that success of an organization is a necessary precondition for emergence and development of organizational culture. Only the assumptions, values, and behavioral norms that have been proven to lead to success can be established as elements of organizational culture. Good organizational performance strengthens the existing cultural values and norms through the process of legitimization. Namely, the organization's success legitimizes the existing assumptions, values, and norms in the organizational culture's content as good, useful, proper, and rational. One of the most important barriers to cultural changes is precisely the fact that the cultural values and norms that want to be changed must first be delegitimized, which is done precisely by proving that they do not lead (any more) to good performance. In addition to all this, one research has shown that even the system of performance measurement leads to creation of specific profiles of cultures, that is, to embedding specific cultural values, specifically the value of accomplishment, above all else. There are hypotheses that implementation of Balanced Scorecard, which is in the view of many authors the best system for performance management and strategy operationalization, impacts incorporating and strengthening of some values in organizational culture, such as value of openness to the environment, value of results and accountability for the results, value of balance and multidimensionality, systematic approach, process perspectives, and value of changes (Bititci et al., 2006).

Some moderating, mediatory factors are often found between organizational culture and performance (Sackmann, 2011). These are usually the components of organization and management that could affect strengthening or weakening of the relations between organizational culture and performance. Communication is one of the moderating factors. It has been identified that communication may strengthen and weaken the relations between mission-oriented and role-oriented cultures and company performance. Leadership in organization is also a mediator in the impact of culture on performance. Depending of the type of leadership, the impact of culture on performance will be stronger or weaker. According to one research, transformational leadership is an important factor which directs the impact of bureaucratic culture on individual work performance of employees. Besides leadership, dedication to the company appears as the factor that shapes the impact of organizational culture on performance. 


\section{Methodological Issues in Research into Impact of Organizational Culture on Performance}

From the earliest days of researching, exploration of the impact of organizational culture on performance has been accompanied by numerous methodological controversies and issues. These issues have largely decreased the significance of the previously described results and discoveries. Methodological issues in research into relations between culture and performance in organizations are manifested primarily in two ways (Wilderom et al., 2000): First, there is the problem of inconsistency which is reflected in the fact that different authors have in their researches used different operative definitions of organizational culture and performance, on the one hand, and different methodologies, on the other. This problem caused that the results of the research have become impossible to accumulate, to expand based on one another and, thus, better and more effectively answer the questions concerning the relationship between culture and performance. The second problem concerns the lack of clarity and deficiencies in the very research methodologies. This problem is manifested in three areas: methodological deficiency in explorations of culture, in explorations of performance, and in explorations of the relationships between them. We will shortly present all three types of methodological deficiencies and issues.

The first issue in research that concerns organizational culture itself is an unclear identification of its content that is supposed to impact performance. Just like there is no single, unique definition of organizational culture, there is also no consensus about what constitutes its content. Therefore, different authors analyze the impact of very different elements of culture on performance.

Second, in many researches, the organizational culture scope is too narrow, when observed both vertically and horizontally. Namely, while researching the impact of organizational culture on performance, many researchers have explored only the values and norms of managers, and not those of other employees. Since organizational structure represents cognitive structures that are mutual to and shared by the majority of employees and managers, such vertical narrowing of culture is simply unacceptable, especially because it is often the case that statements made by management about company values are more "espoused theory" and less "theory in use". When observed horizontally, many researchers have reduced culture to the culture of one company function or sector, whereby they have also reduced its representativeness. The fact that the issue of subcultures and their impact on performance has not been dealt with, in almost any of the existing research, is also particularly problematic. It is reasonable to presume that the function of subcultures, such as production or marketing subcultures, have some impact on organizational performance.

As it turns out, defining of organizational performance is equally difficult task as is the defining of culture and its components. Therefore, one of the key methodological issues comes down to the following question: What is performance? There are two theoretical approaches to defining company performance, and the large majority of researchers has mostly applied only one of them (Wilderom et al., 2000). First, there is the rational goal approach. According to this approach, organizational performance and organizational success are measured by achievements of financial, that is, economical goals of organization, such as profits, return on investment (ROI), company's market capitalization, income, market share, and the like. This approach is the simplest one and it brings the advantage of a relatively easy providing of the needed data and performance appraisal. It does, however, have many disadvantages, such as that it is unidimensional, oriented to the 
past, short-term in perspective, overemphasizing of quantitative while neglecting qualitative criteria of success, bears exposure to the risk of accounting manipulations, and the like. All these disadvantages cause that financial and economic parameters of company's success are to a large extent rendered as pointless. Namely, the company that is very successful today, if its success is measured solely based on its financial indicators, can be highly unsuccessful tomorrow if it is not innovative, not flexible, if it does not motivate its employees, etc. It is precisely this argument that has led to a multidimensional approach in defining of performance. This approach is based on defining of company's success as the degree to which the interests of all or the majority of stakeholders are fulfilled, instead of defining it as fulfilment of the interest of shareholders as the sole stakeholder, which is the characteristic of the previously described rational goal approach. The multiple stakeholders approach implies that a successful company is the one that has got not only good financial indicators, but has also got good parameters in other business areas that are of interest to other stakeholders, such as product innovativeness, customer satisfaction, employee satisfaction, product quality, social responsibility, sustainable development, etc. Besides the obvious advantage of the multidimensional over the rational goal approach, almost all research into culture's impact on performance start from the latter in defining of performance. To make matters worse, the selected parameters of performance that are used in these researches often lack theoretical ground. Researchers do not even bother to derive the performance dimensions they are evaluating from a valid theoretical framework, but they often select those dimensions randomly. If the dimensions were at least chosen according to their practical values, it would lessen the problem. But some researchers do not even state either theoretical or practical reasons for selecting this or that performance dimension being evaluated. Finally, a separate problem is that, in some researches, performance is not evaluated objectively, but perceptively: performance appraisals are given by the very respondents.

There is one more issue related to the previously described one: common method bias (Sackmann, 2011). This issue arises when culture and performance appraisals are gathered from the same sources, and therefore they are not independent. The same respondents evaluate both the culture as well as performance. In such cases, these two independent variables are explored and evaluated based on the information that are not independent. It is reasonable to assume that the appraisal of culture given by one respondent could impact the appraisal of organizational performance given by the same respondent, and vice versa. In this way, the real picture of both culture and performance is being distorted, as is consequently the appraisal of their interconnectedness.

The level of analysis is also an important methodological issue. Namely, research into the impact of organizational culture on performance should, by its nature, be conducted at organizational level. However, some research reaches evaluations of cultural dimensions as well as performance dimensions by collecting the data at individual level, and then aggregating them at organizational level, most commonly through calculating arithmetic mean. There are serious reasons to doubt the methodological validity of the approach in which some cultural value or a parameter at organizational level are calculated as arithmetic mean of their evaluations given by individual members of organization.

A relatively common methodological disadvantage in the research into relations between culture and performance is "fishing" (Wilderom et al., 2000). In some studies of culture's impact on performance, a large number of both different cultural dimensions as well as 
different performances are observed, which is in itself a good thing. It is not a good thing, however, to reach conclusions about their relations based on randomly and unrestrictedly selected pairs of cultural dimensions and performances, instead of on independent, previously defined rules. In this way, the researcher is actually "fishing" for causal relationships between individual dimensions of culture and performance where they do indeed exist.

Absence of longitudinal research and time-lag research is one of the main methodological problems in research into relations between organizational culture and performance (Sackmann, 2011). The real picture of the impact of organizational culture on performance can be obtained only through comparison of the culture in one time period ( $t$ ) with the performance in the following time period $(t+1)$. However, most research conducted thus far are not longitudinal in character, which means that culture and performance are measured and evaluated in the same time period. This practically means that variations in performance that occurred due to the impact of some cultural characteristics in the previous period are ascribed to the impact of the currently existing cultural characteristic.

\section{Conclusion}

The purpose of researching into culture in management is its supposed impact on company performance. Organizational culture, as a system of collective meanings which emerged in the process of social construction of reality, significantly determines the perceptions and interpretations of the organization members, and thereby also their decisions, actions, and interactions. Therefore, organizational culture shapes the behavior of employees and managers in a company, and thereby it also shapes how they perform activities and tasks in the company's business processes. This is why organizational culture is an important determinant of core competence, whereby it influences the ability of the company to gain competitive advantage on the market, which is the key precondition for good performance. Organizational culture, therefore, represents one of the factors of business performances of companies and other types of organization. The aim of this paper is to determine, by reviewing the existing research into the impact of organizational culture on performance, whether this theoretical assumption is correct, that is, whether this impact has also been proven in empirical research.

The review of literature on the organizational culture's impact on performance leads to three conclusions. First, the impact of organizational culture on performance of companies or other organizations does indeed exist, although its intensity is weaker than it was intuitively assumed. Second, since organizational culture and performance are in themselves highly complex and multidimensional variables, hence their relationship is also multilayered, multidimensional, and complex. Third, even though the methodology of the research into organizational culture and performance has, without a doubt, advanced, it is still faulty in some respects. Imperfections in the research methodology also decrease the persuasiveness of the identified impact of organizational culture on performance. 


\section{References}

Alavi, M., Kayworth, T.R., \& Leidner, D.E. (2005). An empirical examination of the influence of organizational culture on knowledge management practices. Journal of Management Information Systems, 22 (3), 191-224.

Alvesson, M. (2002). Understanding organizational culture. London: Sage

Balthazard P., Cooke R.E. \& Porter R.A. (2006). Dysfunctional culture, dysfunctional organization: capturing the behavioral norms that form organizational culture and drive performance. Journal of Managerial Psychology, 21 (8), 709-732.

Baird, K., Harrison, G. \& Reeve, R., (2007). The culture of Australian organizations and its relation with strategy. International Journal of Business Studies, 15 (1), 15-41.

Barney, J. B., \& Clark, D. N. (2007). Resource-based theory: Creating and sustaining competitive advantage. Oxford University Press on Demand

Berson, Y., Oreg, S., \& Dvir, T. (2008). CEO values, organizational culture and firm outcomes. Journal of Organizational Behavior: The International Journal of Industrial, Occupational and Organizational Psychology and Behavior, 29 (5), 615-633.

Bititci, U., Mendibil, K., Nudurupati, S., Garengo, P., \& Turner, T. (2006). Dynamics of performance measurement and organisational culture. International Journal of Operations \& Production Management, 26(12),1325-1350.

Bontis, N. (1999). Managing organizational knowledge by diagnosing intellectual capital: Framing and advancing the state of the field. International Journal of Technology Management, 18(5/6/7/8), 433-462.

Bontis, N. (1998). Intellectual capital - An exploratory study that develops measures and models. Management Decision, 36(2), 63-76.

Brooking, A. (1997). The management of intellectual capital. Long Range Planning, 3(30), 364-365.

Cabrita, M. D. R., \& Bontis, N. (2008). Intellectual capital and business performance in the Portuguese banking industry. International Journal of Technology Management, 43(1-3), pp. 212-237.

Daum, J. H. (2003). Intangible assets and value creation. New York: John Wiley \& Sons.

Deem, J. M., Barnes, B., Segal, S. \& Preziosi R. (2010). The relationship of organizational culture to Balanced Scorecard effectiveness, SAM Advanced Management Journal, 75(4).

Denison, D. R. \& Mishra, A. K. (1995). Toward a theory of organizational culture and effectiveness. Organization Science, 6, 204-223.

Flamholtz E.G. \& Kannan-Narasimhan R. (2005). Differential impact of cultural elements on financial performances. European Management Journal, 23, 50-64.

Freiling J \& Fichtner H. (2010). Organizational culture as the glue between people and organization: A competence-based view on learning and competence building. Zeitschrift für Personalforschung, 24(2), 152-172. 
Giberson, T. R., Resick, C. J., Dickson, M. W., Mitchelson, J. K., Randall, K. R. \& Clark M. A. (2009). Leadership and organizational culture: Linking CEO characteristics to cultural values. Journal of Business Psychology, 24,123-137.

Gregory, B.T, Harris, S.G., Armenakis, A.A. \& Shook, C.L. (2009). Organizational culture and effectiveness: A study of values, attitudes, and organizational outcomes. Journal of Business Research, 62, 673-679.

Ginevičius, R. \& Vaitkūnaitè V. (2008). Analysis of organizational culture dimensions impacting performance. Journal of Business Economics and Management, 4, 201211.

Hamel G. \& Prahald C. (1994).Competing for the future. Boston: Harvard Business School Press.

Henri, J.F. (2006). Organizational culture and performance measurement systems. Accounting, Organizations and Society, 31, 77-103.

Hofstede, G., Neuijen B., Ohayiv D. \& Sanders G. (1990). Measuring organizational culture: A qualitative and quantitative study across twenty cases. Administrative Science Quarterly, 35, 286-316

Klein, A. (2011). Corporate culture: Its value as a resource for competitive advantage. Journal of Business Strategy, 32 (2), 21-28.

Kotter, J. P., \& Heskett, J. L. (1992). Corporate culture and performance, New York, NY: The Free Press

Kwantes, C. T., Arbour, S. \& Boglarsky, C.A. (2007). Organizational culture fit and outcomes in six national contexts: an organizational level analysis. Journal of Organizational Culture, Communications and Conflict, 11(2).

Louis, M.R. (1985). Sourcing workplace cultures: Why, when and how. In: R.H. Kilmann, M.J. Saxton, R. Serpa and Associates, (eds.) Gaining control of the corporate culture. San Francisco: Jossey Bass, pp. 126-136.

Lund, D. B. (2003). Organizational culture and job satisfaction. Journal of Business \& Industrial Marketing, 18 (3), 219-236.

Marr, B. (2006). Strategic performance management - Leveraging and measuring your intangible value drivers. Oxford, Burlington: Elsevier.

Martin, J. (2002). Organizational culture: Mapping the terrain. London: Sage.

Martín de Castro, G., Delgado-Verde, M., López-Sáez, P., \& Navas-López, J. E. (2011). Towards 'an intellectual capital-based view of the firm': Origins and nature. Journal of Business Ethics, 98(4), 649-662.

Martinez, E. A., Beaulieu, N., Gibbons, R., Pronovost, P., \& Wang, T. (2015). Organizational culture and performance. American Economic Review, 105(5), 331-35.

Ouchi, W.G. (1981). Theory Z: How American business can meet the Japanese challenge. Reading, MA: Addison-Wesley.

Peters T.J. \& Waterman R.H., (1982). In search of excellence. New York: Warner Books.

Peterson, M. \& Smith P. (2000). Sources of meaning, organizations and culture: making sense of organizational events. In: N.M. Ashkanasy, C. P.M. Wilderom., and M.F. 
Peterson (eds.) Handbook of organizational culture \& climate, Thousand Oaks: Sage, pp. 101-117.

Pettigrew, A.M. (1979). On studying organizational culture. Administrative Science Quarterly, 24, 570-581.

Porter, M. E. (1980). Competitive Strategy: Techniques for Analyzing Industries and Competitors. The Free Press, New York.

Ranson, S., Hinings B. \& Greenwood R. (1980). The structuring of organizational structures. Administrative Science Quarterly, 25(1), 1-17.

Rokeach, M. (1973). The Nature of human values. New York: Free Press

Sackmann S. (2011). Culture and performance. In N. Ashkanasy, C. P.M Wilderom., \& M.F. Peterson (eds). Handbook of Organizational Culture \& Climate, $2^{\text {nd }}$ ed. Thousand Oaks: Sage,188-225.

Sorensen J.B. (2002). The strength of corporate culture and the reliability of firm performance. Administrative Science Quarterly, 47, 70-91.

Schein E. (2004). Organizational Culture and Leadership. Thousand Oaks: Sage.

Smircich, L. (1983). Organizations as shared meanings. In: L. Pondy, P. Frost, G. Morgan \& T. Dandridge (eds). 1983. Organizational symbolism. Greenwich, CT: JAI, 55-65.

Sonnier, B. M. (2008). Intellectual capital disclosure: High-tech versus traditional sector companies. Journal of Intellectual Capital, 9(4), 705-722.

Stewart, T. A. (1997). Intellectual capital: The new walth of organizations. Bantam Doubleday Dell Publishing group, New York, NY.

Sundać, D., \& Fatur Krmpotić, I. (2009). Measurement and management of intellectual capital. Tourism and Hospitality Management, 15(2), 279-290

Tsui, A. S., Wang, H. \& Yin (2006). Organizational culture in China: An analysis of cultural dimensions and cultural types. Management and Organization Review, 2, 345-376.

Wilderom C., Glunk, U. \& Maslowski, R. (2000). Organizational culture as a predictor of organizational performance. In: N.M. Ashkanasy, C. P.M. Wilderom., and M.F. Peterson, (eds). 2000. Handbook of Organizational Culture \& Climate, Thousand Oaks: Sage, 193-211.

Wright A. (2010). Culture and compensation - Unpicking the intricate relationship between reward and organizational culture. Thunderbird International Business Review, 52(3).

Yarbrough L., Morgan N. A. \& Vorhies D. W. (2011). The impact of product market strategyorganizational culture fit on business performance. Journal of the Academy of Marketing Science, 39, 555-573.

Zheng W., Yang B. \& McLean G.N. (2010). Linking organizational culture, structure, strategy, and organizational effectiveness: Mediating role of knowledge management. Journal of Business Research, 63, 763-771. 